\title{
LA PARTICIPACIÓN DE LOS MUNICIPIOS Y LOS GOBIERNOS REGIONALES EN LOS RECURSOS TRIBUTARIOS DEL ESTADO: UN ESTUDIO PROSPECTIVO*
}

\author{
Juan Carlos Ferrada Bórquez \\ Abogado y Doctor en Derecho \\ Profesor de Derecho Administrativo \\ Universidad Austral de Chile
}

\section{Introducción}

El Gobierno ha venido impulsando desde hace algún tiempo una reforma substancial al sistema de gobierno y administración interior del Estado, especialmente la de base regional, ello con el propósito de alcanzar mayores niveles de descentralización administrativa que impacten positivamente la eficiencia y eficacia de la acción de los poderes públicos, impulsen el desarrollo regional y aumenten la legitimidad de los órganos directivos regionales ${ }^{1}$.

En este marco una de las reformas que se plantea tímidamente, es avanzar en la generación de instrumentos de descentralización fiscal, ya sea por la vía del gasto o por la vía del ingreso, pero que en todo caso permitan una mayor disponibilidad de recursos y aumente la autonomía decisional de los Gobiernos Regionales en la destinación de los mismos ${ }^{2}$. Uno de estos instrumentos posibles de perfeccionar podría ser establecer algún sistema de participación de las regiones en el sistema tributario, ya sea por la vía de crear nuevos tributos de aplicación regional, sustituyendo o no a tributos nacionales actualmente en vigor, o habilitar la coparticipación de las regiones en los tributos generales de la nación hoy percibidos por la Administración central ${ }^{3}$. La experiencia comparada en esta materia es rica y generosa para tomarla como referencia, constituyéndose en un buen parámetro para impulsar reformas substanciales en este ámbito.

\footnotetext{
Este trabajo forma parte del Proyecto DID de la Universidad Austral de Chile N² S-200060, titulado "El ré gimen de gobierno y de administración regional después de la reforma de 1991. Las principales características que presenta y sus limitaciones estructurales".

${ }^{1}$ Ver, en este sentido, El Chile descentralizado que queremos. Un proyecto de todos, Subsecretaría de Desarrollo Regional y Administrativo, junio 2001.

Idem, pp.72-77.

${ }^{3}$ Idem, pp.76-77.
} 
Sin embargo, creemos que antes de avanzar en cualquiera de estas hipótesis, es necesario determinar cuál es el marco que regula actualmente el sistema tributario chileno, que restricciones y limitaciones impone, que mecanismos de descentralización fiscal por vía tributaria considera actualmente y cuáles serían las alternativas que podrían complementarlas. Estas serán precisamente las materias que abordaremos brevemente en las páginas que siguen, advirtiendo desde ya que se trata sólo de una análisis preliminar del tema, que se enmarca en un estudio más amplio de la temática en estudio.

\section{Las bases constitucionales en materia tributaria.}

\section{El principio de legalidad tributaria.}

Un principio capital en materia tributaria es la legalidad impositiva como garantía de los ciudadanos frente al poder, o en términos más estrictos, de la necesidad o reserva de ley para establecer exacciones fiscales a los ciudadanos. Tal principio se inspira en la exigencia política medieval de origen germánico del consentimiento ciudadano (consensus populi) para ciertas materias, manifestado directamente o en forma indirecta a través de sus representantes ${ }^{4}$, de contribuir con su patrimonio a sufragar los gastos de la Corona, o más modernamente, de la Administración estatal. Así, esta exigencia ya aparece en las primeras cartas medievales de reconocimiento de derechos ciudadanos, en términos de condicionar su exigencia a la aprobación previa del "Consejo Común del reino" o del cuerpo de nobles que encarnan la representación de la comunidad, reconociéndole a éstos un derecho de resistencia frente al poder impositivo estatal $\left.\right|^{5}$.

La concepción anterior es recogida por la filosofía política contractualista francesa del siglo XVIII -especialmente Rousseau- y expresada funcionalmente por los revolucionarios franceses en términos de exigencia para ciertas materias, entre las que

\footnotetext{
“Ver, GARCIA DE ENTERRÍA, Eduardo y FERNÁNDEZ, Tomás-Ramón. Curso de Derecho Administrativo, Tomo I, Civitas, Madrid, $7^{a}$ edición, 1996, pp.106-107.

${ }^{5}$ En este sentido, la Carta Magna inglesa de 1215 dispuso en su numeral 12 que "No se impondrán derecho de escudo (scoutage) ni subsidio en nuestro reino, a menos que sea por el Consejo Común de nuestro reino, excepto para redimir nuestra persona, y para armar caballero a nuestro hijo mayor, y para casar una vez a nuestra hija mayor; y para esto no se pagará más que un subsidio razonable. De la misma manera deberá hacerse respecto de los subsidios de los ciudadanos de Londres". Asimismo, el numeral 14 señala: "Y para tener la aprobación del Consejo Común del reino en lo tocante a la fijación de un subsidio (excepto en los tres casos arriba mencionados) o de un derecho de escudo, haremos que sean convocados los arzobispos, obispos, abades, condes y grandes barones del reino, por nuestras cartas selladas; y además de esto haremos que sean convocados, en general, por nuestros sheriffs y alguaciles, todos los demás que dependen de Nos directamente...". Textos tomados de PACHECO GOMEZ, Máximo. Los Derechos Humanos. Documentos básicos, Tomo I, Editorial Jurídica de Chile, Santiago, $3^{2}$ edición, 2000 , p. 41 .
} 
se incluye la potestad impositiva del Estado, la voluntad general de los ciudadanos expresada normativamente en una ley. ${ }^{6}$. De este modo, la declaración francesa de derechos del hombre de 1789 primero y las Constituciones liberales de fines del siglos XVIII y XIX darán expreso reconocimiento a esta garantía para los ciudadanos, en términos dę consagrarlo, algunas cartas más modernas, como un derecho fundamental . Este es precisamente el caso de la Constitución Política chilena de 1980 -en adelante CPR-, que a partir de lo que disponen los Art.19 №20, 60 №14 y 62 incisos $2^{\circ}$ y $4^{\circ}$ numeral $1^{\circ}$. consagra el principio de legalidad tributaria en su más amplia acepción.

Ahora bien, ¿qué implica este principio de legalidad tributaria? Este principio se refiere, en términos más estrictos, a la necesidad o reserva material de ley, en sentido estricto, para abordar esta materia, sin que pueda el poder reglamentario general entrar en forma independiente a tratar dichos contenidos. En otras palabras, el principio de legalidad, entendido en términos de reserva legal va a implicar que el poder público sólo por ley puede imponer ciertas obligaciones que inciden en la libertad o el patrimonio de los ciudadanos -ámbitos históricamente conectados con el principio de reserva legal por su vinculación con la protección de los derechos de los ciudadanos y la proscripción de la tiranía del poder estatal $\left.\right|^{10}$-, ya que sólo el cuerpo representativo de los ciudadanos (parlamento) está legitimado para afectar estos bienes jurídicos, en la medida que el propio procedimiento de elaboración y discusión de la ley garantiza una discusión pública y contradictoria sobre la materia ${ }^{11}$. Esto se expresa en el ámbito tributario como señala SPISSO ${ }^{12}$ - en que sólo la ley debe definir los supuestos y elementos esenciales de la relación tributaria, incluyendo bajo esta denominación los hechos imponibles y los sujetos pasivos de la obligación. Lo anterior no supone, evidentemente, una restricción absoluta a la potestad reglamentaria para actuar en esta materia, sino sólo una restricción a su actuación autónoma o en ámbitos esenciales del tributo, lo que

\footnotetext{
${ }^{6}$ Sobre la conexión intrínseca entre la voluntad de los ciudadanos y la formulación revolucionaria del concepto de ley como expresión concreta de la libertad de los mismos, ver el excelente trabajo GARCIA DE ENTERRIA, Eduardo. La lengua de los derechos. La formación del Derecho público europeo tras la Revolución Francesa, Alianza Universidad, 1995, pp.108-136.

7 El artículo 14 de la Declaración de 1789 señala. "Todos los ciudadanos tienen el derecho de comprobar por sí mismos o por medio de sus representantes, la necesidad de la contribución pública, de consentirla libremente, seguir su empleo, y determinar la cualidad, la cuota, el sistema de cobro y la duración". Texto extraído de PACHECO, M. "Los Derechos Humanos", ob.cit., p. 90.

${ }^{8}$ En el mismo sentido, EVANS DE LA CUADRA, Enrique y EVANS ESPIÑEIRA, Eugenio. Los tributos ante la Constitución, Editorial Jurídica de Chile, Santiago, 1997, pp.50-51.

${ }^{9}$ RUBIO LLORENTE, Francisco. La formal del poder, Centro de Estudios Constitucionales, Madrid, 1997, pp.319322.

${ }^{10}$ GARCIA DE ENTERRIA, E. y FERNÁNDEZ, T-R. Curso de Derecho Administrativo, ob, cit., pp. 232-234.

"Por todos, DE OTTO, Ignacio. Derecho Constitucional. Sistema de fuentes, Ariel, Derecho, $2^{\mathrm{a}}$ edición, $5^{2}$ reimpresión, 1997, pp.153-154.

${ }^{12}$ SPISSO, Rodolfo. Derecho Constitucional Tributario, Ediciones Depalma, Buenos Aires, 1993, pp.193-194.
} 
es coherente con el concepto de reserva relativa que utiliza la doctrina más autorizada ${ }^{13}$ y que ha reconocido expresamente nuestro Tribunal Constitucional en otras materias ${ }^{14}$.

Este principio de reserva legal en materia tributaria -como ya lo señalamos-, está reconocido expresamente en nuestro ordenamiento constitucional, en términos de someter a una norma de rango legal la regulación básica de cualquier tributo. Así, el Art. $19 N^{\circ} 20$ CPR señala que la "...Constitución asegura a todas las personas... la igual repartición de los tributos en proporción a las rentas o en la progresión o forma que fije la ley, que "...en ningún caso la ley podrá establecer tributos manifiestamente desproporcionados o injustos...", que "...la ley podrá autorizar que determinados tributos puedan estar afectados a fines propios de la defensa nacional..." y que "....podrá autorizar que los que gravan actividades o bienes que tengan una clara identificación regional o local puedan ser aplicados, dentro de los marcos que la misma ley señale, por las autoridades regionales o comunales para el financiamiento de obras de desarrollo". Además, ello se complementa con lo establecido por la misma Carta en el Art. 62 en materia de procedimiento de elaboración de la ley, en conexión con lo señalado en el Art, 60 №14 en cuanto a las materias exclusivas de ley, en que dispone que "...las leyes sobre tributos de cualquier naturaleza que sean....sólo pueden tener su origen en la Cámara de Diputados..." y que al Presidente de la Repúhlica corresponde la iniciativa legislativa exclusiva para " 1 ㅇmponer, suprimir, reducir o condonar tributos de cualquier clase $\circ$ naturaleza, establecer exenciones o modificar las existentes, y determinar su forma, proporcionalidad o progresión" (las cursivas son nuestras).

De lo expuesto queda en evidencia que en nuestro sistema jurídico los tributos sólo pueden ser establecidos por ley, exigencia que se entiende a todos los elementos relativos a la existencia y cuantía de la obligación tributaria ${ }^{15}$, es decir, a los elementos esenciales de este tipo de cargas fiscales ${ }^{16}$, ley que deberá cumplir con las exigencias previstas en el texto constitucional. En este sentido, nuestro Excmo. Tribunal Constitucional ha señalado que la Carta de 1980 consagra "la necesidad de que sea la ley y no otra fuente, la que determine los tributos aplicables", atribuyendo así al legislador la responsabilidad de "velar por la proporción y justicia tributaria" que proclama en su Art.19 №20. Además añade que el constituyente "ha sido extremadamente cuidadoso en cuanto a la regulación de los tributos, requiriendo no

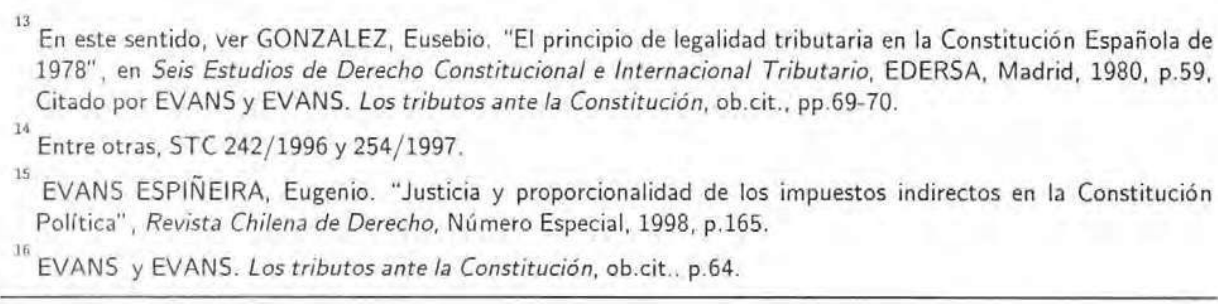


sólo que los elementos esenciales de una obligación tributaria queden comprendidos en la ley misma, sino también que ésta se genere de acuerdo con las exigencias que la misma Constitución puntualiza" (STC 247/1996).

Por otro lado, debemos entender el vocablo tributo utilizado por el constituyente, para estos efectos, en sentido amplio, es decir, englobando "a toda exacción patrimonial impuesta por la ley a las personas en beneficio de la nación, representada por el Estado" ${ }^{17}$. De este modo, se entiende que forman parte de la voz tributo, los impuestos, las tasas y las contribuciones especiales, todas éstos especies de tributos en el ordenamiento jurídico ${ }^{18}$, lo que implica que cualquier tipo de exacción patrimonial impuesta por el Estado debe tener su fuente en la ley. Esto incluye, lógicamente, las patentes y derechos que cobran distintos órganos del Estado, ya que ellos constituyen tributos, en la acepción amplia del término y, como tal, deben ser creados por ley ${ }^{19}$.

\section{El principio de universalidad de los ingresos públicos}

Otro de los principios capitales sobre los que se estructura el sistema tributario chileno, y que es relevante para la materia en estudio, es la universalidad de los ingresos públicos, es decir, la no afectación de los tributos a destinos específicos y determinados o, en términos positivos, la existencia de una caja común de la Nación para percibir los tributos cobrados por el Estado. Este principio general se fundamenta en la necesidad de que los ingresos públicos recaudados por medio de tributos se incorporen a los haberes generales del Estado, sin que sea posible condicionar en forma previa su utilización a un fin específico, ya que de otro modo se rigidizaría indebidamente el manejo de la política fiscal y presupuestaria ${ }^{20}$. En este mismo sentido, el propio Tribunal Constitucional ha declarado -siguiendo a la doctrina nacional (FIGUEROA

${ }^{17}$ EVANS y EVANS. Los tributos ante la Constitución, ob.cit.. p. 64.

${ }^{18}$ Véase, en el mismo sentido, LOPEZ BERENGUER, José. Manual de Derecho Tributario, Dykinson S.L., Madrid, 1989, pp.713 y ss.

${ }^{19}$ En este mismo sentido, el profesor Raúl Bertelsen, miembro de la Comisión de Estudios que redactó la Constitución de 1980 señaló que "tributo es un término genérico que comprende cualquier impuesto, contribución, arancel, derecho o tasa, es decir cualquier prestación que los particulares tengan que satisfacer al Estado..."

19

por lo que naturalmente debemos entender incluidas, dentro de éste concepto, entre otros, a las patentes que deben satisfacer los titulares de concesiones otorgadas por el Estado. Actas Oficiales de la Comisión de Estudios de la Nueva Constitución, sesión 398, 11 de julio de 1978, p.3115.

20

Como señalan EVANS Y EVANS, "lo que prohíbe la Constitución es condicionar un gasto a una recaudación tributaria específica, directa y jurídicamente afectada a un destino vinculado a ese gasto. Las razones que explican la limitación constitucional a la soberania del legislador radican en que la afectación previa impide evaluar año a año las necesidades que la justificaron, pudiendo darse el caso que no sea menester continuar la destinación de los recursos a satisfacerlas, o bien que sea imprescindible aumentar los montos para atenderlas frente a situaciones de emergencia". EVANS y EVANS. Los tributos ante la Constitución, ob.cit., p.101. 
VALDES) que "..lo que se señala y desprende de una interpretación armónica de la norma, y es lo que el constituyente ha querido, es que no haya una relación absoluta dependiente y directa entre lo que se recauda por concepto de impuestos y el destino que se da a lo recaudado. Así, el constituyente quiere evitar un vínculo directo y subordinado de un tributo a un gasto determinado" (STC 219/1995).

Hace excepción al principio general antes enunciado, la afectación de algunos tributos que dispone la propia Constitución a fines propios de la defensa nacional o que graven actividades o bienes que tengan una clara identificación regional o local, los que deberán estar destinados a financiar obras de desarrollo de la respectiva unidad territorial. La excepción anterior se complementa con lo dispuesto en la disposición séptima transitoria de la CPR, que señala que "sin perjuicio de lo dispuesto en el inciso tercero del número 20 del artículo 19, mantendrán su vigencia las disposiciones legales que hayan establecido tributos de afectación a un destino determinado, mientras no sean expresamente derogadas", norma que tiene por objeto dejar subsistentes algunos tributos de afectación directa vigentes a la entrada en vigencia de la Constitución y que, por tanto, seguirán operando plenamente mientras las disposiciones que los han establecido no hayan sido abrogadas expresamente (STC 183/1994). Lo anterior debe entenderse $\sin$ perjuicio que dichas disposiciones legales sufran reformas parciales a algunos de los elementos constitutivos del tributo, en la medida que tales modificaciones no alteran en lo sustancial el tributo establecido y la afectación directa y determinada que se haga de los mismos(STC 203/1994).

Ahora bien, la disposición transitoria antes señalada, constituye una excepción calificada sólo en cuanto a la imputación de los dineros recaudados por el tributo, debiendo en lo demás conformarse el tributo a los criterios y principios constitucionales previstos en el articulado permanente.

\section{Los tributos de afectación local o regional}

1.- Ámbito de aplicación de la habilitación constitucional de excepción a las autoridades regionales y comunales

Como ya lo señalamos, el Art.19 №20 CPR contempla una habilitación al legislador para, si lo estima conveniente, conceder normativamente una potestad a las autoridades regionales o comunales para aplicar tributos con clara identificación regional o local, destinadas a financiar obras de desarrollo. Esta disposición supone la presencia de algunos elementos básicos, a saber:

a) Lo autorizado por el constituyente es la atribución por ley a las autoridades comunales o regionales de una potestad de ejecución concreta y determinada 
en el ámbito tributario ${ }^{21}$, la aplicación de un tributo, lo que no implica, evidentemente, una habilitación a las autoridades regionales o locales para crear o establecer tributos, lo que es lógica consecuencia del principio de legalidad tributaria antes comentado ${ }^{22}$. Así, es evidente que los gobiernos regionales no tienen una capacidad impositiva directa, sino sólo lo que la Constitución prevé es una habilitación al legislador para crear tributos con destinación regional, correspondiendo la aplicación de los mismos, si así lo determina el legislador, a los municipios y los gobiernos regionales. En este sentido, los Art. $5^{a}$ letra h de la Ley №18695 Orgánica Constitucional de Municipalidades -en adelante LOCM- y 20 letra i de la Ley №19175 Orgánica Constitucional de Gobierno y Administración Regional -en adelante LOCGAR- contemplan como atribuciones de los municipios y de los gobiernos regionales, respectivamente, la potestad para aplicar, dentro de los marcos que la misma ley señale, los tributos objeto de la habilitación legislativa.

b) Los tributos que pueden ser entregados en su aplicación a las autoridades territoriales antes señaladas, son aquellos que tengan una clara identificación local o regional, entre los que se encuentran la explotación de los recursos naturales no renovables ${ }^{23}$. No tendrían tales características, según se desprende de lo fallado por el Tribunal Constitucional, aquellos tributos que pudiendo sus hechos gravados tener relación con el desarrollo de una actividad comercial o particular en la comuna o región, no tenga una "clara identificación" con la misma (STC 212/1995) ${ }^{24}$.

c) Los recursos captados por los municipios y gobiernos regionales a través de los tributos antes individualizados, sólo podrán estar destinados a financiar obras de desarrollo, término este que debe interpretarse en términos restrictivos por el legislador. De este modo, no le está permitido al legislador omitir la conexión entre estos recursos y el fin constitucional asignado (STC $50 / 1988$ y $212 / 1995)$, ni menos destinarlos a financiar otros gastos de la corporación municipal o del gobierno regional. De este modo, queda excluida

${ }^{24}$ En este punto debe recordarse que lo señalado en el Art.19 N²0 CPR sufrió una modificación en el año 1991 (Ley 19097) con motivo de la reforma regional, ya que extendió la excepción calificada a este principio general de no afectación, los tributos que gravan actividades o bienes que tengan una clara identificación regional.

22

Constitución Politica de la República de Chile, Leyes anotadas y concordadas, Diario Oficial de la República de Chile, Santiago, 1992, p. 37.

23

Idem, p. 37

En este caso se trataba del tributo establecido en el Art.41 del Decreto Ley N2825 de 1974, sobre Impuesto a la Venta y Servicios, que establece que corresponde pagar en la transferencia de un vehículo motorizado, actividad que el tribunal consideró no cubierto por la habilitación constitucional del Art.19 №20 CPR (STC 212/1995), 
la posibilidad de que esta afectación a los tributos de carácter excepcional sirva para financiar los gastos de funcionamiento de los municipios y los gobiernos regionales, los que deben solventarse con cargo los recursos asignados anualmente en la Ley de Presupuestos o con sus recursos propios, según sea el caso ${ }^{25}$.

Esta uniformidad tributaria postulada por el constituyente, parece ser una expresión de la propia configuración política del Estado de Chile -Estado unitario-, donde la existencia de un único régimen constitucional o legal se considera un requisito constitutivo de este tipo de Estado ${ }^{26}$. No obstante, ello contrasta con habilitaciones más amplias a las entidades territoriales en la potestad impositiva, ya sea en Estados unitarios o cuasi federales. Así, en países como Colombia, Bolivia y España, por nombrar algunos, se contemplan potestades más amplias a los gobiernos regionales y comunales para crear y/o aplicar tributos en diversas materias y con finalidades fiscales - parafiscales, lo que implica dotar a aquellas entidades de recursos propios que permitan una gestión administrativa más ágil y flexible.

\section{Los tributos de afectación local}

Actualmente podemos encontrar una serie de tributos establecidos en beneficio de la Administración local, que hacen operable la excepción al principio de universalidad de los ingresos públicos antes descrito. Así tenemos, entre los más importantes, el impuesto establecido como permiso a la circulación de vehículos (Art. 12 del DL 3063/1979, la Ley de Rentas Municipales), el impuesto a los bienes raíces (Ley №17235/1969 sobre Impuesto Territorial), las patentes municipales al ejercicio de actividades comerciales o industriales (Art.23 DL 3063/1979) y las patentes de alcoholes (Ley 17105/1969 sobre Alcoholes, Bebidas Alcohólicas y Vinagres). Estos tributos generan, en conjunto, los principales ingresos propios que perciben los Municipios, sin perjuicio de establecerse la imputación de un porcentaje de los mismos -porcentaje que varía en las comunas de mayor poder económico- al Fondo Común Municipal (Art.13 LOCM). Pero veamos brevemente en que consiste cada uno de ellos y como estos se encuentran establecidos en beneficio de las municipalidades.

El permiso de circulación a los vehículos es un impuesto anual que grava a los vehículos que transitan por las calles, caminos y vías públicas en general, con un monto fijo o una tasa progresiva y acumulativa sobre el precio corriente de la plaza, según el caso (Art.12 DL 3063/1979). Este tributo, no obstante estar establecido en beneficio

\footnotetext{
${ }^{25}$ Ver, en este mismo sentido, Constitución Política de la República de Chile, ob.cit., pp.37-38.

${ }^{26}$ En este sentido, ver VERDUGO, Mario y GARCIA, Ana María. Manual de Derecho Político. Instituciones Políticas, Editorial Jurídica de Chile, Santiago, 1979, tomo I, pp.223 y ss.
} 
de las municipalidades, sólo el 37,5\% ingresa a las arcas del municipio que lo recauda, destinándose el otro $62,5 \%$ al Fondo Común Municipal (Art.14 №2 LOCM) ${ }^{27}$.

Por su parte, el impuesto a los bienes raíces, es un tributo que grava a los inmuebles que se sitúan dentro de la comuna, con una tasa fija de quince por mil del avalúo fiscal del bien, con exenciones parciales o totales, en relación al avalúo mismo, la ubicación geográfica del inmueble o la destinación social que tiene el mismo. Este tributo es recaudado directamente por la Tesorería General de la República o por los bancos comerciales autorizados por ésta, de acuerdo a las boletas de pago emitidas por el Servicio de Impuestos Internos en los meses de abril, junio, septiembre y noviembre de cada año (Art.22 Ley 17235 y 47 del Código Tributario). Si bien el tributo está establecido en beneficio directo de las municipalidades, sólo el $40 \%$ constituirá ingreso propio de cada municipalidad, salvo las Municipalidades de Santiago, Providencia, Las Condes y Vitacura, en que el referido ingreso propio será sólo del $35 \%$ de lo recaudado", entregándose el 60 ○ $65 \%$ restante al Fondo Común Municipal (Art.37 DL $3063 / 1979$ y 14 №1 LOCM) ${ }^{28}$.

Otro tributo establecido en beneficio de las municipalidades son las patentes comerciales e industriales que gravan los establecimientos situados en su comuna que realicen algunas de las actividades a que se refiere el Art.23 DL 3063/1979. Este tributo tiene como base imponible el capital propio destinado a la actividad gravada, no obstante su monto será fijo o afecto a una tasa variable (entre 2,5 por mil y 5 por mil, según lo determine la municipalidad respectiva), dependiendo de la actividad de que se trate y de si el contribuyente está obligado o no a llevar contabilidad general (Art.24 DL 3063/1979). En todo caso, el monto del tributo no podrá ser inferior a 1 UTM ni superior a 8.000 UTM. El beneficiario del tributo es la municipalidad respectiva, no obstante la Municipalidad de Santiago sólo percibe el $45 \%$ de lo recaudado y las Municipalidades de Providencia, Las Condes y Vitacura el $35 \%$, ingresando los restantes al Fondo Común Municipal (Art. 14 №3 LOCM).

Por último, y como una especialidad de lo anterior, están las patentes de alcoholes, que son aquellas que gravan el ejercicio de toda industria, comercio o cualquier otra actividad lucrativa relacionada con las bebidas alcohólicas y que están establecidas en beneficio directo del municipio donde se sitúa el inmueble que desarrolla dicha actividad (Art.33 DL 3063/1979 y 140 Ley 17105/1969). No obstante, al igual que en el caso de las patentes comerciales e industriales, las Municipalidad de Santiago y de Providencia, Las Condes y Vitacura, sólo percibirán el 45 y $35 \%$. respectivamente, ingresando el exceso al Fondo Común Municipal (Art.14 №3 LOCM).

\footnotetext{
${ }^{27}$ Recuérdese que esta disposición fue modificada por la Ley №19704 de diciembre de 2000.

${ }^{28}$ Texto modificado por la Ley $\mathrm{N}^{2} 19.074$.
} 
El monto a pagar en este tipo de tributos es un valor fijo, de acuerdo a una escala que identifica a cada tipo de establecimiento, sin perjuicio del establecimiento de montos menores en caso de patentes temporales (Art. 24 DL3063/1979 y 140, 146 y 159 Ley 17.105/1969).

Como se puede apreciar fácilmente, los principales tributos de afectación local actualmente vigentes no cumplen con las exigencias constitucionales establecidas en el Art.19 №20 -identificación local y destinación al financiamiento de obras de desarrollo- y más bien su juridicidad responde a su conformidad con la disposición séptima transitoria de la Constitución. En este sentido podemos concluir que, al menos en materia de tributos de afectación local- no se ha concretado la previsión del constituyente $y$, por tanto, en esta materia seguimos amparados en el régimen tributario preconstitucional salvaguardo, entendemos que de modo temporal, por la normativa transitoria dada por el constituyente.

\section{Los tributos de afectación regional}

En relación con los tributos de afectación regional, se sostiene como ejemplos emblemáticos dos casos de reciente creación y desarrollo: las patentes sobre concesiones mineras y las patentes sobre concesiones de energía geotérmica. En ambas situaciones, el legislador ha dispuesto que los ingresos captados por esta vía vayan en directo beneficio de los gobiernos regionales, no obstante las compensaciones e imputaciones posteriores de esos mismos recursos al Fondo Nacional de Desarrollo Regional.

En relación a la primera de éstas -las patentes mineras-, recordemos que el texto constitucional establece en su Art. 19 No24 CPR que corresponde a la ley establecer un régimen de amparo de toda concesión minera, ya sea de exploración o de explotación. A este respecto, el artículo 12 de la Ley №18.097 de Concesiones Mineras establece que dicho régimen de amparo consistirá "en el pago anual y anticipado de una patente a beneficio fiscal", entregando al Código de Minería la determinación de su forma y monto. Por su parte el Código de Minería, Ley №18.248, establece en su título $X$ (artículos 142 y siguientes) el monto anual de dicha patente, el que, por regla general, será equivalente a $1 / 10$ de Unidad Tributaria Mensual -en adelante UTM- por cada hectárea completa, en el caso de las concesiones mineras de explotación. En cambio, si la concesión es de exploración, dicha patente alcanzará la suma de un quincuagésimo de UTM. Sin embargo, el legislador ha establecido una excepción calificada para los titulares de pertenencias cuyo interés económico principal resida en las sustancias no metálicas o en los placeres metalíferos que existan en ellas y los titulares de pertenencias constituidas sobre sustancias existentes en salares, para quienes la patente será equivalente a un trigésimo de UTM. 
Ahora bien, no obstante que el propio código del ramo se encarga de reiterar, en su artículo 163, que "el valor de las patentes mineras será de exclusivo beneficio fiscal", con posterioridad a la Reforma Constitucional de 1991 (Ley №19097) -que precisamente habilitó la afectación regional de determinados tributos-, se dictó la Ley №19143, cuyo artículo único hace aplicación de la excepción contemplada en el inciso cuarto del citado Art. 19 №20 de la CPR, disponiendo la distribución entre las regiones y comunas del país, de una cantidad igual al producto de las patentes de amparo de las concesiones mineras a que se refiere el título $X$ del Código de Minería, en una proporción de un $70 \%$ y un $30 \%$ respectivamente. El porcentaje correspondiente a las regiones se incorporará anualmente a la cuota del Fondo Nacional de Desarrollo Regional que le corresponda en el presupuesto nacional a la región donde tenga su oficio el Conservador de Minas en cuyo registro esté inscritas el acta de mensura o la sentencia constitutiva de las concesiones mineras que den origen a las patentes respectivas. Para estos efectos la Ley de Presupuestos de cada año deberá incluir en el presupuesto del Gobierno Regional respectivo las cantidades que correspondan a cada región.

Algo similar a lo antes descrito se reitera más recientemente con los recursos captados por las patentes de concesiones de explotación de energía geotérmica, a las que se refiere la Ley N19657. A estos efectos, se entiende por aprovechamiento de energía geotérmica, aquella que se utiliza en el calor interno de la tierra en forma de vapor o de agua caliente existente en la corteza terrestre, ya sea en yacimientos cercanos a la superficie o en profundidades que no excedan el límite económico de utilización, excluyendo las aguas termales. Respecto de estas concesiones se establece la obligación de amparo para el concesionario de explotación, lo que se cumple mediante las obligaciones establecidas en el decreto de concesión y el pago de una patente anual a beneficio fiscal. El monto de dicha patente será equivalente a un décimo de UTM por cada hectá rea completa de extensión territorial comprendida por la concesión.

Sin embargo, lo relevante de dicha norma para nosotros en este momento, es lo dispuesto en el Art. 33 de la misma, en el sentido que se recoge íntegramente el criterio seguido por el legislador de 1992, en cuanto a que el destino y distribución de los recursos captados por el Estado por el pago de la patente beneficiará a las regiones y las comunas, en una cantidad igual al producto de las patentes anuales pagadas por los titulares de concesiones, correspondientes a sus respectivos territorios. Efectivamente, la Ley №19657 dispone que el $70 \%$ de dicha cantidad se incorporará proporcionalmente en la cuota del FNDR que anualmente le corresponda, en el presupuesto nacional de la o las regiones en cuyo territorio esté situada la concesión, y el $30 \%$ restante corresponderá a las municipalidades de las comunas en que estén situadas las concesiones. Para estos efectos, el Servicio de Tesorerías pondrá a 
disposición de las regiones y municipalidades correspondientes, dentro del mes subsiguiente a su recaudación, los recursos provenientes del pago de patentes.

Este último caso quizás es el ejemplo más importante en esta materia, porque constituye una buena muestra de que la habilitación específica que hace al constribuyente el legislador en materia de afectación de tributos (Art.19 N²0 CPR), comienza a tener una aplicación concreta en nuestro ordenamiento y da cuenta de la confirmación del incipiente criterio descentralizador fiscal que se va desarrollando en la legislación chilena, no siendo ya una aplicación temporal de una norma transitoria de excepción como el caso de los tributos de afectación local. Esta observación es más relevante, si se considera que en el proceso de discusión de la Ley sobre concesiones de energía geotérmica, se aprecia una unanimidad en esta materia, lo que constituye un buen augurio del futuro desarrollo de esta potestad tributaria a nivel regional ${ }^{29}$.

No obstante lo señalado anteriormente es necesario puntualizar que tanto las patentes mineras como las patentes geotérmicas constituyen pasos muy débiles en el proceso de descentralizador por la vía de los ingresos a nivel regional, ya sea por el volumen de los recursos fiscales involucrados, el ámbito geográfico de impacto de los mismos y el mecanismo dispuesto de contabilización y asignación a través del propio Fondo Nacional de Desarrollo Regional. Sin duda, estos elementos constituyen un obstáculo a una efectiva descentralización regional, pero no anulan la importancia de la medida.

Ahora bien, sin perjuicio de todo lo expuesto, es preciso dejar constancia que no obstante que estos dos casos constituyen ejemplos de descentralización fiscal por la vía de los ingresos y, por tanto, instrumentos de generación de recursos propios para los gobiernos regionales, que las patentes mineras, tanto para el legislador ${ }^{30}$, la doctrina ${ }^{31} y$ la jurisprudencia ${ }^{32}$ no son consideradas tributos para todos los efectos legales, en la

${ }^{29}$ La referencia esté hecha a la Comisión de Mineria del Senado. Ver Legislatura 336², extraordinaria. Sesión $35^{2}$, en martes 10 de marzo de 1998 y al Informe de la Comisión Mixta (Oficio a la H. Cámara de Diputados N² 15075) recaido en el proyecto de ley sobre establecimiento de normas para el otorgamiento de concesiones de exploración y explotación de energía geotérmica. (Boletín $N^{2}$ 571-08). Las materias, sobre las cuales se presentaron mayores problemas y que excepcionalmente fueron objeto de votación dividida en la Comisión Mixta fueron: la naturaleza jurídica atribuida a la energía geotérmica; la intervención de la Comisión Nacional de Energía; tramitación de la solicitud de concesión de exploración o explotación y el contenido del decreto que las otorga; finalmente, el contenido del derecho de aprovechamiento de aguas. Como se puede observar no se encuentra presente la discusión en torno al punto que aquí nos ocupa.

${ }^{30}$ El artículo único de la Ley $\mathrm{N}^{2} 19143$ establece expresamente que las patentes mineras "....no constituyen tributos..."

${ }^{31}$ Por todos, LIRA ALLE, Samuel. Curso de Derecho de Minería, Editorial Jurídica de Chile, Santiago, 1992. p. 235 y OSSA BULNES, Juan Luis. Derecho de Minería, Editorial Jurídica de Chile, Santiago, 1999, $3^{2}$ edición, pp. 258-259.

${ }^{32}$ Entre otras SCS de 9 de septiembre de 1959, Revista de Derecho y Jurisprudencia, tomo 56, sección 12a, p. 287. 
medida que la finalidad de la patente no es obtener ingresos para el fisco ni está establecida como un requisito para ejercer una profesión o industria, sino solamente establecer un mecanismo de amparo que expresa el ánimo del concesionario de conservar su derecho de concesión minera. En este contexto, las patentes mineras no constituyen una aplicación de la habilitación legislativa prevista en el Art.19 №20 CPR ya que no son tributos propiamente tal como lo exige el constituyente. Análogo razonamiento se podría emplear para las patentes de concesiones geotérmicas, por lo que si bien el legislador nada ha dicho, y -hasta donde conocemos- la doctrina y jurisprudencia no han tenido oportunidad de pronunciarse, no habría razones para sostener una solución distinta de la dada para las patentes mineras.

En suma habrá que concluir que actualmente no existen casos concretos que sean aplicación del mecanismo de descentralización fiscal previsto en la Constitución para los gobiernos regionales, lo que es preocupante si se desea avanzar en un fortalecimiento de los gobiernos regionales como instancias de gestión y desarrollo en la región.

\section{Algunas propuestas de profundización de la descentralización fiscal a nivel regional}

\section{Fundamentación general}

Es un criterio bastante extendido en la doctrina nacional y comparada que para desarrollar un auténtico proceso de descentralización territorial del poder, es necesario generar instrumentos fiscales que fortalezcan la autonomía financiera de las unidades territoriales ${ }^{33}$. Esto implica no sólo dotar a los entes territoriales de recursos suficientes para satisfacer los requerimientos de los ciudadanos que la ley ha puesto en la esfera de sus atribuciones (descentralización por la vía del gasto), sino además, establecer mecanismos de generación directa de recursos para el financiamiento de los gobiernos regionales o locales, los que, en lo posible, reflejen un principio de corresponsabilidad fiscal entre éstos y el Estado central ${ }^{34}$. Esto permitirá establecer una sana relación entre las acciones de las autoridades territoriales y las demandas de los ciudadanos, lo que se reflejará en las decisiones de ingresos y gastos que adopte la administración regional o local.

Precisamente estos objetivos han llevado al Gobierno del Presidente Lagos ha formular la descentralización fiscal como uno de los objetivos políticos de su

\footnotetext{
${ }^{33}$ Por todos, ADAME MARTINEZ, Francisco. El sistema de financiación de las comunidades autónomas de régimen general, Comares, Granada, 1998, pp.28-29.

En el mismo sentido, UTRILLA DE LA HOZ, A. y CUADRADO ROURA, J.R. Financiación autonómica. La incidencia del nuevo sistema en la Comunidad de Madrid, Civitas, Madrid, 1997, p.31.
} 
administración. En este sentido se ha señalado que "la propuesta global para el área fiscal apunta a generar un sistema financiero descentralizado más autónomo y equitativo, lo cual conduce al fortalecimiento de ingresos y gastos tanto para las regiones como para las comunas y a generar una cultura de rendición de cuentas que asegure la mayor transparencia de los gobernantes respecto a su gestión y al compromiso ciudadano frente al objetivo del desarrollo de su propio territorio" ${ }^{35}$. Tal propósito no se ha cumplido hasta ahora, más aún, como ha quedado en evidencia, no existe ningún tributo a nivel local c regional que haya desarrollado la previsión constitucional pertinente, lo que habla claramente acerca de la urgencia dada por el gobierno y el parlamento a esta materia en el último decenio.

Lo anterior nos lleva a formular algunas propuestas para avanzar en este terreno, las que deben mirarse como ideas muy básicas que requieren un mayor análisis y discusión para su aplicación.

\section{Primera propuesta: La participación de los gobiernos regionales en los tributos generales del Estado.}

Una de las propuestas posibles a implementar sería establecer un mecanismo de coparticipación financiera entre la Administración Central y las administraciones regionales sobre alguno o algunos de los tributos establecidos al ejercicio de ciertos actos jurídicos en un territorio determinado. Esta modalidad existe en el derecho comparado en el ámbito regional -España, Colombia o Brasil, por nombrar algunos casos-, estableciéndose coparticipaciones en impuestos a la compraventa de bienes o la prestación de ciertos servicios o sobre la celebración de ciertos actos jurídicos documentados. En el primero de los casos, la coparticipación de los gobiernos regionales en el IVA, para el caso chileno, el objetivo es que parte de los recursos tributarios que se captan por el ejercicio de actividades de intermediación comercial en la región se queden en la misma región, de modo tal que exista un incentivo directo a las autoridades regionales al impulso del desarrollo de nuevos proyectos productivos y en un mayor celo en el control de la evasión tributaria. Esta participación en el IVA podría ser del orden del 1 - $2 \%$ que podría operar ya en el marco de los porcentajes actualmente vigentes o como una sobretasa regional que pudiera ser aplicada por las autoridades, previa habilitación legislativa, en especial cuando se trate de actividades económicas con fuerte impacto en la conservación de los recursos naturales disponibles en la región.

${ }^{35}$ El Chile descentralizado que queremos, op.cit, p. 72. 
Esta propuesta, creemos, podría tener algunos efectos económicos positivos sobre la recaudación tributaria, en la medida en que la organización administrativa regional asume una mayor preocupación por la captación efectiva de estos tributos, ya que los recursos necesarios para ejercer sus funciones está relacionado directamente con la obtención de los mismos. Sin embargo, presentaría esta propuesta algunos inconvenientes derivados de la concentración efectiva de la actividad económica que existe en nuestro país, ya que en aquellas zonas donde la actividad es mayor, se podrían obtener mayores recursos. Esto podría aumentar la brecha entre zonas ricas y pobres, ya que los recursos tributarios se quedarían en las zonas donde ya existe actividad productiva.

Ahora bien, desde el punto de vista jurídico, para poder llevar a cabo esta medida se requeriría probablemente de una reforma constitucional, en la medida que el tributo coparticipado no tendría una relación directa con actividades o bienes que tengan una clara identificación regional o local $\left.\right|^{36}$. Ello es $\sin$ perjuicio que la coparticipación se podría establecer respecto de tributos que tengan esta naturaleza como sería el caso de actividades económicas relacionadas con la explotación de ciertos recursos naturales-, caso en el que bastaría una ley que desarrollara el precepto general establecido en el Art.19 N²0 CPR.

\section{Segunda propuesta: Establecimiento de nuevos tributos de carácter regional o} traspaso de tributos generales ya existentes al patrimonio regional

Una segunda alternativa que se puede plantear es el establecimiento de nuevos tributos de carácter regional, que digan relación con una actividad o bien de clara identificación regional o el traspaso íntegro de la recaudación de un tributo a la administración regional, cumpliendo con las exigencias constitucionales previstas. En el primer caso estamos ante actividades económicas que se desarrollan en la región y que actualmente no tienen un tributo específico pero que generan utilidades efectivas a los particulares que la desarrollan. Este sería el caso, por ejemplo, de los juegos de azar cuya explotación hoy día beneficia sólo a la municipalidad que lo entrega en concesión, pero no está afecto a tributos que tengan un claro impacto regional. Esto genera algunas distorsiones e inequidades intra regionales evidentes, ya que los beneficios económicos asociados a la explotación de esta actividad lúdica sólo se radican en el municipio correspondiente, lo que no parece equitativo para el resto de las comunas de la región. Así no puede extrañarnos que exista una verdadera competencia por parte de

\footnotetext{
${ }^{36}$ Téngase en consideración que, como ya se señaló anteriormente, el Tribunal Constitucional declaró en su oportunidad la inconstitucionalidad de un precepto legal que pretendia establecer en beneficio municipal, el $50 \%$ del impuesto establecido a la transferencia de un vehículo motorizado, en la medida que dicha operación, no obstante celebrase en la comuna beneficiaria, no cumplia con la característica de identificación local a que se refiere el Art.19 N220 CPR (STC 212/1995).
} 
muchas comunas del país para acceder a una autorización legal para entregar en concesión una sala de juegos, lo que no se corresponde con un desarrollo equilibrado y coherente de este mercado a nivel nacional.

Otra materia que pudiera eventualmente considerarse como hecho gravado, destinando su recaudación a los gobiernos regionales, es la contaminación de ciertos recursos naturales de especial valoración ambiental, como el aire o el agua. En este sentido, la experiencia de las Comunidades Autónomas españolas ha sido muy rica, destacándose la creación de impuestos ambientales con finalidad fiscal o parafiscal en diversas regiones ${ }^{37}$. Sin duda $-y$ así lo ha señalado la doctrina-, este es el campo en que la potestad tributaria regional puede tener un mayor desarrollo, en la medida que el propio hecho gravado es un bien que probablemente irá adquiriendo una mayor relevancia política y económica y actualmente no está afecto a ninguna carga tributaria,

El segundo caso planteado, el traspaso total e íntegro de tributos específicos a la administración regional-mecanismo que opera regularmente en otros países, supone la entrega de la aplicación, control y supervisión del impuesto a organizaciones burocráticas regionales, las que requieren de una capacitación y adecuación previa a las exigencias administrativas de este tipo de función. En el caso chileno, esto implicaría el traspaso de personal capacitado desde la administración tributaria central a los gobiernos regionales o la celebración de convenios administrativos entre ésta y los gobiernos regionales para hacer operativo este mecanismo. Esto podría implementarse para ciertos impuestos especiales, como el impuesto al tabaco, los combustibles o la celebración de ciertos actos jurídicos formales. De este modo, los recursos captados por el Estado a la adquisición, explotación, uso o consumo de ciertos bienes y servicios iría en directo beneficio de los gobiernos regionales donde se desarrollan éstos.

Esta segunda alternativa presenta similares inconvenientes a la coparticipación tributaria analizada anteriormente, ya que las regiones que presentan mayores índices de actividad comercial serían las más beneficiadas por este tipo de reformas. No obstante, la ventaja se presenta en cuanto a que se genera un efectivo mecanismo de corresponsabilidad entre las funciones asignadas a la administración regional y los recursos necesarios para llevarlas a cabo, lo que puede hacer más eficiente su captación y uso.

${ }^{37}$ ADAME, F. El sistema de financiación de las comunidades autónomas de régimen general, op.cit., pp.193-214. 


\section{Conclusiones}

De todo lo expuesto en las páginas precedentes, se pueden extraer algunas conclusiones relevantes:

1. En el ordenamiento jurídico chileno existe una aplicación muy estricto de los principios de legalidad tributaria y de universalidad de los ingresos públicos, que restringe excesivamente la posibilidad de crear tributos de afectación regional o local.

2. La habilitación restrictiva que da el constituyente al legislador para crear tributos de afectación local o regional está condicionada específicamente a la ejecución de obras de desarrollo. Esto constituye una limitación excesiva en esta materia, lo que hace que en la práctica no existan tributos de este tipo, salvo los preconstitucionales amparados por la disposición séptima transitoria de la Constitución, que no cumplen con las exigencias del articulo permanente.

3. Ni aún en el caso de los tributos de afectación regional se ha desarrollado el precepto, en la medida que los únicos casos que pudieran considerarse (patentes mineras y geotérmicas), no tienen la naturaleza jurídica de tributos, por tanto tampoco son aplicación del Art.19 №20.

4. Urge una discusión más acabada sobre una descentralización fiscal por la vía de los ingresos a nivel local y regional, que considere alguna alternativa de gestión directa, por parte de los gobiernos regionales, de algún tributo o de la recaudación parcial de éste, que permita un desarrollo real de la autonomía financiera de los entes subnacionales, dimensión ineludible de un real proceso de descentralización territorial del poder.

5. Una profundización del proceso descentralización fiscal por la vía de los ingresos va a requerir, probablemente, de reformas constitucionales sustanciales que permitan hacer operable un sistema de financiamiento ágil y flexible para las entidades subnacionales. 